\title{
Determining the minimum required uranium carbide content for HTGR UCO fuel kernels
}

Jacob W. McMurray*,1, Terrence B. Lindemer ${ }^{2}$, Nicholas R. Brown ${ }^{3}$, Tyler J. Reif ${ }^{4}$, Robert N. Morris $^{5}$, John D. Hunn ${ }^{5}$

\author{
1. Materials Science and Technology \\ Division, Oak Ridge National \\ Laboratory, Oak Ridge, TN 37831-6063 \\ 2. MPi Business Solutions, Inc., Knoxville \\ TN 37915 \\ 3. Reactor and Nuclear Systems Division, \\ Oak Ridge National Laboratory, Oak \\ Ridge, TN 37831-6165 \\ 4. X-Energy, LLC, 7701 Greenbelt, $M D$ \\ 20770 \\ 5. Fusion and Materials for Nuclear \\ Systems Division, Oak Ridge National \\ Laboratory, Oak Ridge, TN 37831-6093
}

A B S T R A C T

Three important failure mechanisms that must be controlled in high-temperature gascooled reactor (HTGR) fuel for certain higher burnup applications are SiC layer rupture, $\mathrm{SiC}$ corrosion by $\mathrm{CO}$, and coating compromise from kernel migration. All are related to high $\mathrm{CO}$ pressures stemming from $\mathrm{O}$ release when uranium present as $\mathrm{UO}_{2}$ fissions and the $\mathrm{O}$ is not subsequently bound by other elements. In the HTGR kernel design, CO buildup from excess $\mathrm{O}$ is controlled by the inclusion of additional uranium apart from $\mathrm{UO}_{2}$ in the form of a carbide, $\mathrm{UC}_{\mathrm{x}}$ and this fuel form is designated $\mathrm{UCO}$. Here general oxygen balance formulas were developed for calculating the minimum $\mathrm{UC}_{\mathrm{x}}$ content to ensure negligible $\mathrm{CO}$ formation and applied to $15.5 \%$ enriched UCO taken to $16.1 \%$ actinide burnup. Required input data were obtained from CALPHAD chemical thermodynamic models and the Serpent 2 reactor physics and depletion analysis tool. The results are intended to be more accurate than previous estimates by including more nuclear and chemical factors, in particular the effect of transmuted $\mathrm{Pu}$ and $\mathrm{Np}$ oxides on the oxygen distribution as the fuel kernel composition evolves with burnup.

This manuscript has been authored by UT-Battelle, LLC under Contract No. DE-AC05-00OR22725 with the U.S. Department of Energy. The United States Government retains and the publisher, by accepting the article for publication, acknowledges that the United States Government retains a nonexclusive, paid-up, irrevocable, world-wide license to publish or reproduce the published form of this manuscript, or allow others to do so, for United States Government purposes. The Department of Energy will provide public access to these results of federally sponsored research in accordance with the DOE Public Access Plan (http://energy.gov/downloads/doe-public-access-plan).

*corresponding author, email: mcmurrayjw1@ornl.gov 


\section{Introduction}

It has been established that pressure vessel failure [1] and CO corrosion [2-4] as well as tristructural isotropic (TRISO) coating compromise from kernel migration $[2,3]$ are important failure mechanisms for high temperature gas-cooled reactor (HTGR) fuel. These phenomena can be predicted as a function of $\mathrm{CO}$ formation using thermodynamic arguments based on the initial composition of the fuel kernel, where $\mathrm{O}$ (liberated when uranium present as $\mathrm{UO}_{2}$ fissions) reacts with the surrounding carbon if not bound by other elements with higher oxygen affinity $[2,3,5]$. In the uranium-carbon-oxygen (UCO) kernel design, $\mathrm{CO}$ formation is mitigated by the inclusion of additional uranium as a carbide, $\mathrm{UC}_{\mathrm{x}}$. Conventionally, the $\mathrm{UC}_{\mathrm{x}}$ phase is substoichiometric $\mathrm{UC}_{2}$ designated $\mathrm{UC}_{2-\mathrm{x}}$. However, any form of $\mathrm{UC}_{\mathrm{x}}$ in the presence of excess $\mathrm{C}$ available in the buffer at HTGR temperatures will form, from the standpoint of thermodynamics, $\mathrm{UC}_{2-\mathrm{x}}$ (or $\mathrm{U}_{2} \mathrm{C}_{3}$ depending on temperature) and therefore the arguments presented here in this work apply to $\mathrm{UC}_{\mathrm{x}}$ generally.

The added $\mathrm{UC}_{\mathrm{x}}$ provides additional material that will form oxides more readily than carbon. Prior efforts in the literature have been made to estimate the required proportion of $\mathrm{UC}_{\mathrm{x}}$ relative to $\mathrm{UO}_{2}$ using simplified chemistry [2,3]. Advances in computational capabilities and the development of new more sophisticated thermodynamic and burnup models merit revisiting these calculations. By including more nuclear and chemical factors it is the aim of this work to produce higher fidelity predictions. Further, the effect of transmutation products, like $\mathrm{Pu}$ and $\mathrm{Np}$, on the oxygen distribution are included for the first time.

One possible benefit of refining the calculation is the option for minimizing the amount of $\mathrm{UC}_{\mathrm{x}}$ in the $\mathrm{UCO}$ kernel so that more of the metallic fission products are oxidized, which more effectively retains them in the kernel relative to their carbide forms. However, UCO kernel designers must consider possible deviations in kernel properties for a given fabrication process and balance the negative impact of $\mathrm{CO}$ formation against any positive impact of reducing the inventory of various metal carbides. The purpose of this work is not to recommend a UCO kernel composition, which would be dependent on reactor design and fabrication control, but rather to outline an approach for determining the minimum $\mathrm{UC}_{\mathrm{x}}$ content in UCO-TRISO fuel necessary for mitigating $\mathrm{CO}$ production using state-of-the art methods. This is accomplished by combining CALPHAD (CALculation of PHase Diagrams) thermodynamic modeling [6-9] with the Monte Carlo neutron transport and depletion tool, Serpent 2,[10] used for burnup simulations.

\section{Approach}

For this paper, we define the limiting lower $\mathrm{UC}_{\mathrm{x}}$ content in a UCO kernel to be the minimum $\mathrm{UC}_{\mathrm{x}}$ needed for a given burnup to maintain an acceptably low oxygen potential, $\mu_{\mathrm{O}_{2}}$, to avoid excessive $\mathrm{CO}$ pressures ( $\mathrm{p}_{\mathrm{CO}}$ ), as well as the so-called "amoeba effect" due to thermal migration of $\mathrm{UO}_{2}$ into the buffer region and ultimately the IPyC and $\mathrm{SiC}$ layers. It has been suggested that lanthanide diffusion through $\mathrm{SiC}$ is avoided when these elements and Y, collectively referred to hereafter as Ln's, are bound and 
immobilized as oxides; experimental evidence supports this [2, 8]. It has been conjectured that fission product (FP) carbides diffuse much faster through $\mathrm{SiC}$ and the carbon layers than their relatively immobile oxide(s) $[2,3,11,12]$. Therefore, a minimum $\mathrm{UC}_{\mathrm{x}}$ could be beneficial by potentially allowing for a sufficiently high $\mu_{\mathrm{O}_{2}}$ to oxidize the Ln's while at the same time holding it low enough to avoid significant $\mathrm{CO}$ production.

\subsection{Burnup simulations}

Burnup simulations are fundamental to the approach and, among other influences, depend upon the fuel geometry, composition, and the neutron spectrum over the irradiation period. To illustrate the methodology for determining the initial minimum $\mathrm{UC}_{\mathrm{x}}$ content, a prismatic HTGR block with a maximum burnup of $16.1 \%$ fissions per initial metal atom (FIMA) was used, the details of which are found in Table 1. In principle, the approach requires iteration using the elemental inventory as a function of burnup together with thermodynamic and mass balance arguments detailed below (assuming the neutron spectrum is fairly constant). However, for this case as shown in Fig. 1, the elemental inventory per fission for the oxide formers depend very weakly on the initial $\mathrm{UC}_{\mathrm{x}}$ content over the range of 3.8 to 20 mole $\%$ that bound the minimum. Thus, iteration was not deemed necessary. The burnup simulation results for a 3.8 mole $\% \mathrm{UC}_{\mathrm{x}}$ composition gives a highly accurate approximate result compared to the converged solution from interation with much less computational overhead.

The Monte Carlo neutron transport and depletion analysis tool Serpent 2 [10] was utilized to generate fission product boundary conditions and inputs for the computational thermodynamic software FactSage ${ }^{\circledR}$ program [8] using the example configuration of a prismatic HTGR block. It is noted that these scoping calculations are not intended to be representative of all possible HTGR designs, but rather to demonstrate this methodology and approach for a reasonably representative configuration. These reactor physics calculations assume a constant temperature and do not account for thermal or thermomechanical feedback effects.

The example was taken as a standard Modular High Temperature Gas-cooled Reactor (MHTGR) block geometry with $15.5 \%$ enriched UCO fuel [13], similar to the definition of a recently developed benchmark problem [14]. The geometry values for the neutronics and burnup calculations are shown in Table 1 . The MHTGR block geometry modeled in the calculations is shown in Figure 2. A periodic boundary condition was used in the calculation with no burnable absorbers. For these scoping calculations, ENDF/B-VII.0 nuclear data was used [15], noting that improvements have been made to both the ${ }^{12} \mathrm{C}$ radiative capture cross section and fission yields in the more recent ENDF/B-VII.1 library [16]. The nuclear data is all taken at a temperature of $900 \mathrm{~K}$, with the exception of the thermal neutron scattering data for graphite, which is used at $1000 \mathrm{~K}$. Data for 1341 nuclides was included in the depletion calculations.

Three compositions of UCO were selected for a parametric study spanning the expected parameter space of $\mathrm{UO}_{2}(80 \% / 90 \% / 96.2 \%)$ and $\mathrm{UC}_{1.9}(20 \% / 10 \% / 3.8 \%)$ molar content. 
An example neutron flux spectrum from the analysis is shown in Figure 3 for Beginningof-Life (BOL) and End-of-Life (EOL) conditions, considered to be 0\% FIMA and 16.1\% FIMA fuel burnup in the context of this study.

\subsection{Thermodynamic calculations}

Due to the abundance of $\mathrm{C}$ present in the buffer region that encompasses the fuel kernel in a TRISO-coated particle, the $\mathrm{O}$ distribution equations that govern the analysis are based on the Ellingham-Richardson diagram for the carbides (over the temperature range of interest) given in Fig. 4. This figure was generated using the FactSage thermodynamic database [8] and a model for fluorite-structure urania solution, (U,Pu, $\mathrm{Ln}) \mathrm{O}_{2-\mathrm{x}}$, with dissolved Ln oxides [17-24]. Figure 4 shows that Ln's, excluding Eu, are oxidized first, followed by $\mathrm{BaC}$ as $\mathrm{BaZrO}_{3}, \mathrm{UC}_{\mathrm{x}}$ phase, $\mathrm{SrC}$ as $\mathrm{SrZrO}_{3}, \mathrm{EuC}_{2}$ and finally $\mathrm{ZrC}$ as $\mathrm{ZrO}_{2}$. The plot also indicates the oxygen-to-metal ratio $(\mathrm{O} / \mathrm{M})$ for the urania solution should remain below 1.950 for FIMA of $16.1 \%$ to avoid oxidizing $\mathrm{SiC}$ (should the inner pyrocarbon layer crack and expose it to the kernel system).

The details of the thermodynamic calculations for the urania solution are given in Table 2. The Ln's and $\mathrm{Pu}$ dissolve in $\mathrm{UO}_{2-\mathrm{x}}$ with a $\mu_{\mathrm{O}_{2}}$ below that of $\mathrm{Zr}$ up to an $\mathrm{O} / \mathrm{M}$ of 1.947 resulting in an effective $\mathrm{O} / \mathrm{M}$ for the $\mathrm{Ln}$ 's and $\mathrm{Pu}$, or $\Theta^{1}$, of 1.55 for oxidation of all $\mathrm{Zr}$. A further $\Theta$ increase up to 1.61 would be acceptable to avoid conversion of $\mathrm{SiC}$ to $\mathrm{SiO}_{2}$. This allows for computing bounding compositions for $\mathrm{UC}_{\mathrm{x}}$ initial content and anticipated $\mathrm{CO}$ pressures as shown in Fig. 5. It should be noted that $\Theta$ changes with burnup and the bounds must be computed for each particular case.

\subsection{Oxygen distribution equations}

To determine the amount of oxygen released and thus the necessary getter material content, in this case $\mathrm{UC}_{\mathrm{x}}$, using the principle of conservation of mass the following equations are operative for full consumption of $\mathrm{UC}_{\mathrm{x}}$ :

$$
\begin{array}{lr}
n_{O}=2 f_{U O_{2}}+(2-\Theta) f y_{P u}+f y_{N p}-\Theta f y_{L n}-2 f y_{Z r}-f\left(y_{S r}+y_{B a}\right) & 1 \\
n_{U C_{x}}=n_{U C_{x}}^{i}-\frac{n_{O}}{2}-f_{U C_{x}} & 2 \\
f=f_{U O_{2}}+f_{U C_{x}} & 3
\end{array}
$$

\footnotetext{
${ }^{1}$ In reality $\Theta>1.5$ results from a combination of $\mathrm{O} /(\mathrm{Ce}+\mathrm{Pu})>1.5$ and $\mathrm{O} / \mathrm{U}>2$. The mathematical simplification presented here is for consistency with [3] T. Tiegs, T. Lindemer, T. Henson, J. Nucl. Mater., 99 (2-3) (1981) 222-34.
} 
$F=\frac{f}{\left(n_{U O_{2}}^{i}+n_{U C_{x}}^{i}\right)}$

where $n_{O}$ is the moles of freed $\mathrm{O}$. The molar fissions per $\mathrm{UO}_{2}$ and $\mathrm{UC}_{\mathrm{x}}$ are $f_{U O_{2}}$ and $f_{U C_{x}}$ respectively with $f$ being the total and FIMA represented by $F$. The $y_{i}$ are elemental inventory per $f$ (or $F$ ) as determined from the codes as a function of $f$ (or $F$ ) for the specific kernel composition and burnup. The oxidation state of the Ln's and $\mathrm{Pu}$ in the fluorite urania solution is represented by $\Theta$. The initial and running total of $\mathrm{UO}_{2}$ and/or $\mathrm{UC}_{\mathrm{x}}$ in moles are $n_{j}^{i}$ and $n_{j}$ respectively.

The first term in Eqn. 1 represents $\mathrm{O}$ release from fissioning of $\mathrm{UO}_{2}$ (or bred in $\mathrm{Pu}$ as an oxide) while the second and third correspond to the freeing of $\mathrm{O}$ from the fact that ${ }^{238} \mathrm{U}$ is transmuted to $\mathrm{Pu}$ and $\mathrm{Np}$ existing as either $\mathrm{PuO}_{\Theta}$ or $\mathrm{NpO}$. For simplicity and due to the lack of sufficient thermodynamic data, $\mathrm{Np}$ is conservatively taken to only form $\mathrm{NpO}$ in this oxygen potential range. The remaining terms represent the binding of $\mathrm{O}$ to the Ln's, $\mathrm{Sr}$, and $\mathrm{Ba}$ fission products. They are treated as composite totals as a function of $f$ (or $F$ ).

The burnup simulations give the result of each fission event corresponding to a $\mathrm{U}$ or $\mathrm{Pu}$ atom and the $y_{i}$ are fit using a least squares method to the output to facilitate representing this relation up to $16.1 \%$ FIMA. The relevant equations resulting from this approach are summarized in Table 3; note the consistency in that the zero intercept values are essentially identical to the fission-product yield for ${ }^{235} \mathrm{U}$ as they should be.

Combining Eqns. 1 - 4 with the initial moles of $U$ set unity, i.e. $n_{U C_{x}}^{i}+n_{U O_{2}}^{i}=1$ such that $f / m o l e=F$ then solving for $n_{U C_{x}}$ equal to zero leads to Eqn. 5:

$x_{U C_{x}}=F\left(1+\frac{(2-\Theta) y_{P u}+y_{N p}-\Theta y_{L n}-2 y_{Z r}-\left(y_{S r}+y_{B a}\right)}{2}\right)$

where $x_{U C_{x}}$ is the minimum mole fraction of $\mathrm{UC}_{\mathrm{x}}$ needed in fresh fuel to oxidize all the fission products up to and including $\mathrm{Ba}$ as a function of $F$.

\section{Results and discussion}

This approach for the present example analysis gives 5.1 to 5.5 mole $\% \mathrm{UC}_{\mathrm{x}}$ as the minimum required initial content to maintain an acceptably low $\mu_{\mathrm{O}_{2}}$ and avoid significant $\mathrm{CO}$ production. These values are calculated using $\Theta=1.55$ and 1.61 respectively. The upper and lower $\Theta$ 's correspond to calculated equilibrium oxygen potentials whereby $\mathrm{Zr}$ $(\Theta=1.55)$ and $\operatorname{SiC}(\Theta=1.61)$ just begin to oxidize. Traditionally, sufficient $\mathrm{UC}_{\mathrm{x}}$ has been added to the kernel to avoid above-atmospheric $\mathrm{CO}$ pressure and the "amoeba" behavior, thus precluding failure via the predominant mechanisms discussed above. 
Evidence, discussed in detail below, suggests that designing a fuel kernel close to the minimum $\mathrm{UC}_{\mathrm{x}}$ content range could potentially improve performance of the HTGR TRISO particle with regards to Eu retention. Whether kernels can be produced within appropriate tolerances to exercise this option is still an open question and the subject of on-going research at Oak Ridge National Laboratory.

The behavior of Eu is different from the other lanthanides in that it is present as a carbide instead of an oxide as long as the $\mathrm{UO}_{2}-\mathrm{UC}_{2-\mathrm{x}}$ equilibrium is present, as is illustrated in Fig. 4. While Eu is not a high yield FP, it has been measured to be one of the highest concentration FPs existing outside of UCO TRISO particles after irradiation testing [25]. A particularly distinctive differentiation between the behavior of the lanthanides Eu and Ce appears in Bullock's [12] measurement of time-dependent release defined as diffusion through the $\mathrm{SiC}$ layer. (Note that Horsley et al [26] reported that $\mathrm{UO}_{2}$ particles irradiated to $5.8 \%$ fima were measured to contain $\mathrm{CO}$ amounts that they calculated to result in 10.5 $\mathrm{MPa} \mathrm{CO}$ at $1400^{\circ} \mathrm{C}$.) For $\mathrm{Eu}$, the behavior at $1500^{\circ} \mathrm{C}$ was generally consistent with the thermodynamic predictions in that there was greater release from fuel particles with $\mathrm{UC}_{2}$ and $\mathrm{UC}_{0.4} \mathrm{O}_{1.6}$ kernels presumably containing $\mathrm{EuC}_{2}$, while that from fuel particles with $\mathrm{Eu}_{2} \mathrm{O}_{3}$ in $\mathrm{UO}_{2}$ kernels was $\sim 6 \%$. Percentage release of $\mathrm{Ce}$ at $1500^{\circ} \mathrm{C}$ from $\mathrm{UC}_{2}$ kernels containing $\mathrm{CeC}_{2}$ was similar to $\mathrm{EuC}_{2}$ in $\mathrm{UC}_{2}$ and $\mathrm{UC}_{0.4} \mathrm{O}_{1.6}$ kernels. However, at the end of burnup, the molar $\mathrm{Ce} / \mathrm{Eu}$ ratio in the kernel would be $\sim 40$, so the molar release of $\mathrm{Ce}$ at $1500^{\circ} \mathrm{C}$ was correspondingly larger.

As mentioned earlier, from a thermodynamic standpoint the resulting $\mathrm{UC}_{2-\mathrm{x}}$ (from the initial $\mathrm{UC}_{\mathrm{x}}$ present) should be consumed before $\mathrm{EuC}_{2}$ initiates oxidation. This leads to Eqn. 6 which gives an approximation of $F_{E u}$, the FIMA at which Eu will no longer exist as a carbide assuming $\mathrm{Sr}$ and $\mathrm{Ba}$ exist as ternary zirconates.

$$
F_{E u}=\frac{x_{U C_{x}}}{\left(1-\frac{\Theta y_{L n}+3\left(y_{S r}+y_{B a}\right)-(2-\Theta) y_{P u}-y_{N p}}{2}\right)}
$$

As calculated, this occurs at 10.9 to $11.7 \%$ FIMA for $\Theta=1.5$ and 5.13 to 5.50 initial mole $\% \mathrm{UC}_{\mathrm{x}}$. The thermodynamic analysis shows that while $\mathrm{Pu}$ and $\mathrm{Ln}$ dissolution into $\mathrm{UO}_{2}$ can result in increased oxidation of the fluorite solution, at this burnup a $\Theta>1.5$ is calculated to have a $\mu_{\mathrm{O}_{2}}$ value above that of $\mathrm{EuC}_{2}$. Therefore, $\mathrm{EuC}_{2}$ is predicted to begin oxidation with between 554 and 591 micromoles of Eu generated per mole initial U.

The present thermodynamic and nuclear calculations reveal several general characteristics of the simulated irradiation. The ${ }^{235} \mathrm{U}$ fission naturally dominates initially. This isotope is $\sim 60 \%$ consumed by $16.1 \%$ FIMA. As illustrated in Fig. 6, it contributes to $\sim 30 \%$ of the fissions occurring at $16.1 \%$ FIMA with the balance coming primarily from ${ }^{239} \mathrm{Pu}$ and ${ }^{241} \mathrm{Pu}$. Also, the integral molar $\mathrm{O}$ release with burnup described by Eqn. 1 has two components: (1) the residual $\mathrm{Pu}$ and $\mathrm{Np}$ having $\mathrm{O} / \mathrm{M}<2$ and (2) fissioning of ${ }^{235} \mathrm{U},{ }^{239} \mathrm{Pu}$ and ${ }^{241} \mathrm{Pu}$ and subsequent binding of $\mathrm{O}$ from the oxide forming FPs that accompany this event. 
Breaking Eqn. 1 into its two components and again setting the initial sum of $\mathrm{UO}_{2}$ and $\mathrm{UC}_{\mathrm{x}}$ to unity, the $\mathrm{O}$ release per FIMA from transmutation alone is:

$$
y_{O}^{\text {trans }}=\left[(2-\Theta) y_{P u}+y_{N p}\right]
$$

where $y_{i}$ 's are implicit functions of $F$ (see Table 3). This results in a slightly decreasing (see Fig. 1) but substantial source of $O$ release as the irradiation proceeds for low enriched $U$. Including more precise details of this this phenomenon differentiates this work from previous similar analyses.

The second component results from fissioning of the actinide oxides and $\mathrm{O}$ uptake by the oxide forming FPs; it is the first term along with the second half of Eqn. 1 and as a function of FIMA it is:

$$
y_{o}^{f i s s i o n}=\frac{2 F_{U O_{2}}-\Theta F y_{L n}-2 F y_{Z r}-F\left(y_{S r}+y_{B a}\right)}{F}
$$

Note that $y_{O}^{\text {fission }}$ constantly increases with FIMA because there are not enough metallic FPs to bind all the $\mathrm{O}$ (see Fig. 1). Thus, $\mathrm{UC}_{\mathrm{x}}$ is needed to getter the excess $\mathrm{O}$ that is liberated from the sum of these two sources.

Finally, many fissions are from $\mathrm{Pu}$ isotopes but from an $\mathrm{O}$ release perspective whether or not $\mathrm{U}$ is first transmuted to $\mathrm{Pu}$ before the event is irrelevant and only affects the $\mathrm{O}$ distribution calculations via FP inventories.

\section{Conclusions}

General oxygen balance relations given by Eqns. $1-5$ were derived for calculating the minimum amount of $\mathrm{UC}_{\mathrm{x}}$ in $\mathrm{UCO}$ fuel needed to preclude the failure mechanisms resulting from high $\mathrm{O}_{2}$ and $\mathrm{CO}$ pressures. Input data were obtained from thermodynamics and reactor physics calculations capturing more nuclear and chemical factors compared to past analyses. For example, a CALPHAD model for the urania solution [17-24] with dissolved $\mathrm{Pu}$ and $\mathrm{Ln}$ 's provides a better representation of the $\mu_{\mathrm{O}_{2}}-$ $\mathrm{O} / \mathrm{M}$ relationship. Further, included for the first time were the detailed effects of both burnup and residual concentrations of $\mathrm{Pu}$ and $\mathrm{Np}$ oxides. The present approach was applied to UCO HTGR fuel enriched to $15.5 \%$ FIMA and taken to $16.1 \%$ FIMA. The results indicate 5.1 to 5.5 mole $\% \mathrm{UC}_{\mathrm{x}}$ as the minimum initial content needed to maintain acceptably low $\mathrm{CO}$ pressure.

Since Eu has been measured [12] to be one of the FPs with the highest fraction the TRISO particles after irradiation testing, it may be desirable to minimize the $\mathrm{UC}_{\mathrm{x}}$ fraction in order to oxidize Eu at the earliest possible burnup when concentrations are as low as possible and thus mitigate Eu transport through the SiC layer. Immobilizing Eu has the 
potential to reduce the radionuclide release to an even greater level than is currently observed. This can be viewed as an approach to design optimization and would aid in the production of a superior fuel and as a technical description of fuel behavior. However, the deviations in kernel compositions for a given fabrication process must be taken into account as excessive $\mathrm{p}_{\mathrm{CO}}$ leads to catastrophic failure.

Past analyses have neglected the effect of transmutation products on determining the required $\mathrm{UC}_{\mathrm{x}}$ content. Tiegs et al. [3] give reasonably similar results but the value stated for $\Theta$ is too high for low burnup fuel according the thermodynamic calculations presented here. Nevertheless, the fission yields in that work, when used to calculate FP inventory, show qualitative agreement with the present simulation.

\section{Acknowledgements}

The authors wish to acknowledge the review, aid, and technical insight of Dr. Fred Montgomery and Dr. Tyler Gerczak at Oak Ridge National Lab. This work was funded by a U.S. Department of Energy Office of Nuclear Energy Advanced Reactor Concept Cooperative Agreement Award led by X-Energy, LLC. 


\section{References}

[1] W. J. Kovacs, K. Bongartz, D. T. Goodin, Nucl. Technol., 68 (3) (1985) 344-54.

[2] F. Homan, T. Lindemer, E. Long Jr, T. Tiegs, R. Beatty, Nucl. Technol., 35 (2) (1977) 428-41.

[3] T. Tiegs, T. Lindemer, T. Henson, J. Nucl. Mater., 99 (2-3) (1981) 222-34.

[4] K. Minato, T. Ogawa, S. Kashimura, K. Fukuda, I. Takahashi, M. Shimizu, Y.

Tayama, J. Mater. Sci., 26 (9) (1991) 2379-88.

[5] T. Lindemer, ORNL/TM-2002/133, September, (2002)

[6] SGTE Substances Database Version 2, http://www.thermocalc.com/TCDATA.htm

[7] CALPHAD, http://www.thermocalc.com/academia/researchers/calphad/

[8] C. W. Bale, P. Chartrand, S. A. Degterov, S. Eriksson, K. Hack, R. B. Mahfoud, J. Melancon, A. D. Pelton, S. Petersen, CALPHAD, 26 (2002) 189.

[9] A. T. Dinsdale, CALPHAD, (1991) 317-425.

[10] J. Leppänen, M. Pusa, T. Viitanen, V. Valtavirta, T. Kaltiaisenaho, Annals of Nuclear Energy, 82 (2015) 142-50.

[11] R. Bullock, J. Kaae, J. Nucl. Mater., 115 (1) (1983) 69-83.

[12] R. Bullock, J. Nucl. Mater., 125 (3) (1984) 304-19.

[13] M. A. Pope, Idaho National Laboratory, INL/EXT-12-26423, (2012)

[14] G. Strydom, A. Epiney, A. Alfonsi, C. Rabiti, Nucl. Technol., 193 (1) (2016) 15-35. [15] M. Chadwick, P. Obložinský, M. Herman, N. Greene, R. McKnight, D. Smith, P. Young, R. MacFarlane, G. Hale, S. Frankle, Nuclear data sheets, 107 (12) (2006) 29313060.

[16] M. Chadwick, M. Herman, P. Obložinský, M. E. Dunn, Y. Danon, A. Kahler, D. L. Smith, B. Pritychenko, G. Arbanas, R. Arcilla, Nuclear Data Sheets, 112 (12) (2011) 2887-996.

[17] C. Guéneau, N. Dupin, B. Sundman, C. Martial, J. C. Dumas, S. Gosse, S. Chatain, F. De Bruycker, D. Manara, R. J. M. Konings, J. Nucl. Mater., 419 (2011) 145-67. [18] S. M. Lee, T. W. Knight, J. W. McMurray, T. M. Besmann, J. Nucl. Mater., 473 (2016) 272-82.

[19] J. McMurray, D. Shin, T. Besmann, J. Nucl. Mater., 456 (2015) 142-50. [20] J. W. McMurray, Thermodynamic Modeling of Uranium and Oxygen Containing Ternary Systems with Gadolinium, Lanthanum, and Thorium, PhD Thesis, University of Tennessee, Knoxville, 2014.

[21] J. W. McMurray, Thermodynamic assessment of the Pr-O system, Journal of the American Ceramic Society; submitted for publication.

[22] J. W. McMurray, S. Hirooka, T. Murakami, K. Suzuki, J. T. White, S. L. Voit, A. T. Nelson, B. W. Slone, T. Besmann, K. J. McClellan, M. Kato, Thermodynamic assessment of the U-Ce-O system, Journal of Nuclear Materials; submitted for publication.

[23] J. W. McMurray, D. Shin, B. W. Slone, T. M. Besmann, J. Nucl. Mater., 452 (1-3) (2014) 397-406.

[24] J. W. McMurray, C. M. Silva, J. Nucl. Mater., 470 (2016) 111-8.

[25] P. A. Demkowicz, J. D. Hunn, R. N. Morris, I. van Rooyen, T. Gerczak, J. M. Harp, S. A. Ploger, AGR-1 PIE Final Report, Idaho National Laboratory (INL), Idaho Falls, ID (United States), (2015) 
[26] G. Horsley, G. Weldrick, J. Turnbull, R. Shipp, J. Am. Ceram. Soc., 59 (1 - 2) (1976) 1-4. 
Table 1. Parameters for the neutronics and burnup calculations [13].

\begin{tabular}{lll}
\hline Parameter & Value & Unit \\
\hline UCO enrichment & 15.5 & $\%$ \\
TRISO packing fraction & 35.0 & $\%$ \\
Cylindrical compact radius & 0.625 & $\mathrm{~cm}$ \\
Power density & 67.8 & watt/gram heavy metal \\
Large coolant channel radius & 0.794 & $\mathrm{~cm}$ \\
Small coolant channel radius & 0.635 & $\mathrm{~cm}$ \\
Unit cell pitch & 1.88 & $\mathrm{~cm}$ \\
Block flat-to-flat dimension & 36.0 & $\mathrm{~cm}$ \\
Fuel kernel radius & 0.02125 & $\mathrm{~cm}$ \\
Buffer thickness & 0.01000 & $\mathrm{~cm}$ \\
IPyC thickness & 0.00400 & $\mathrm{~cm}$ \\
SiC thickness & 0.00350 & $\mathrm{~cm}$ \\
OPyC thickness & 0.00400 & $\mathrm{~cm}$ \\
UCO density & $10.65-10.85$ & $\mathrm{~g} / \mathrm{cm}^{3}$ \\
Buffer density & 1.0 & $\mathrm{~g} / \mathrm{cm}^{3}$ \\
PyC density & 1.9 & $\mathrm{~g} / \mathrm{cm}^{3}$ \\
SiC density & 3.2 & $\mathrm{~g} / \mathrm{cm}^{3}$
\end{tabular}


Table 2. Inputs used to determine the equilibrium oxygen potential for fluorite urania with dissolved fission and transmutation products at 16.1\% FIMA as a function of O/M (or $\Theta$ ). No thermodynamic data for Pm and Eu in solution with $\mathrm{UO}_{2}$ has been assessed; these were therefore aggregated as $\mathrm{Nd}$ to a first approximation.

\begin{tabular}{|c|c|c|c|}
\hline Element & $\begin{array}{l}\text { Total moles } \\
\text { at } 16.1 \% \\
\text { FIMA }\end{array}$ & $\begin{array}{l}\text { Mole fraction in } \\
(\mathrm{U}, \mathrm{Ln}) \mathrm{O}_{2-\mathrm{x}} \\
\text { solution }\end{array}$ & Comment \\
\hline $\mathrm{U}$ & 0.7967 & 0.8722 & $\begin{array}{l}\text { Includes remaining un-fissioned } \mathrm{U} \text { from } \\
90 \% \mathrm{UO}_{2} \text { and } 10 \% \mathrm{UC}_{2} \text { initial molar } \\
\text { compositions with all remaining } \mathrm{UC}_{2} \\
\text { oxidized to } \mathrm{UO}_{2}\end{array}$ \\
\hline $\mathrm{La}$ & 0.0097 & 0.0107 & \\
\hline $\mathrm{Nd}, \mathrm{Pm}, \mathrm{Sm}, \mathrm{Eu}$ & 0.0364 & 0.0398 & $\begin{array}{l}\text { No thermodynamic data for } \mathrm{Pm}, \mathrm{Sm} \text {, and } \mathrm{Eu} \\
\text { in solution with } \mathrm{UO}_{2} \text { has been assessed. } \\
\text { Treated as Nd to a first approximation. }\end{array}$ \\
\hline $\operatorname{Pr}$ & 0.0086 & 0.0094 & \\
\hline $\mathrm{Ce}$ & 0.0198 & 0.0217 & \\
\hline $\mathrm{Y}$ & 0.0056 & 0.0061 & \\
\hline $\mathrm{Pu}$ & 0.0366 & 0.0401 & \\
\hline
\end{tabular}


Table 3. Comparison of the constant values in [3] and the equations from this work derived from a least squares fit to the elemental inventory per FIMA as a function of FIMA over the range $3 \%$ to $16.1 \%$ generated for $15.5 \%$ enriched $96.2 \% \mathrm{UO}_{2}-3.8 \%$ $\mathrm{UC}_{1.9}$ molar composition burnup calculation.

\begin{tabular}{ccc}
\hline Relation & $\mathrm{R}^{2}$ value & Tiegs et al. \\
\hline$y_{L n}=-0.1929 F+0.5339$ & 0.989 & $y_{L n}=0.542$ \\
$y_{P u}=-1.1663 F+0.4041$ & 0.989 & $N / A$ \\
$y_{Z r}=-0.2987 F+0.3048$ & 0.992 & $y_{Z r}=0.3400$ \\
$y_{S r}=-0.1975 F+0.0955$ & 0.978 & $y_{S r}=0.0956$ \\
$y_{B a}=0.0637 F+0.0678$ & 0.951 & $y_{B a}=0.0677$ \\
$y_{N p}=0.0898 F+0.0089$ & 0.969 & $N / A$
\end{tabular}



Figure 1. Elemental inventory for oxide formers at $20 \% \mathrm{UC}_{1.9}$ (solid), $10 \% \mathrm{UC}_{1.9}$ (colored, dashed), and 3.8\% $\mathrm{UC}_{1.9}$ (dots) and freed $\mathrm{O}$ (black, solid) per cumulative fissions as a function of \% FIMA. The black dashed lines are computed using the relations in Table 3 . The inset is a close up view corresponding to the black box enclosing the Pu inventory from 15 to $16 \%$ FIMA in order to aid the reader in differentiating between the lines that are, for the most part, difficult to distinguish. The open and closed circles are calculated using $\Theta=1.61$ in Eqns. 7 and 8 showing the $O$ released from fission and transmutation contributions independently to illustrate the importance of including the latter effect in the determination of the total $\mathrm{O}$ redistributed with burnup.

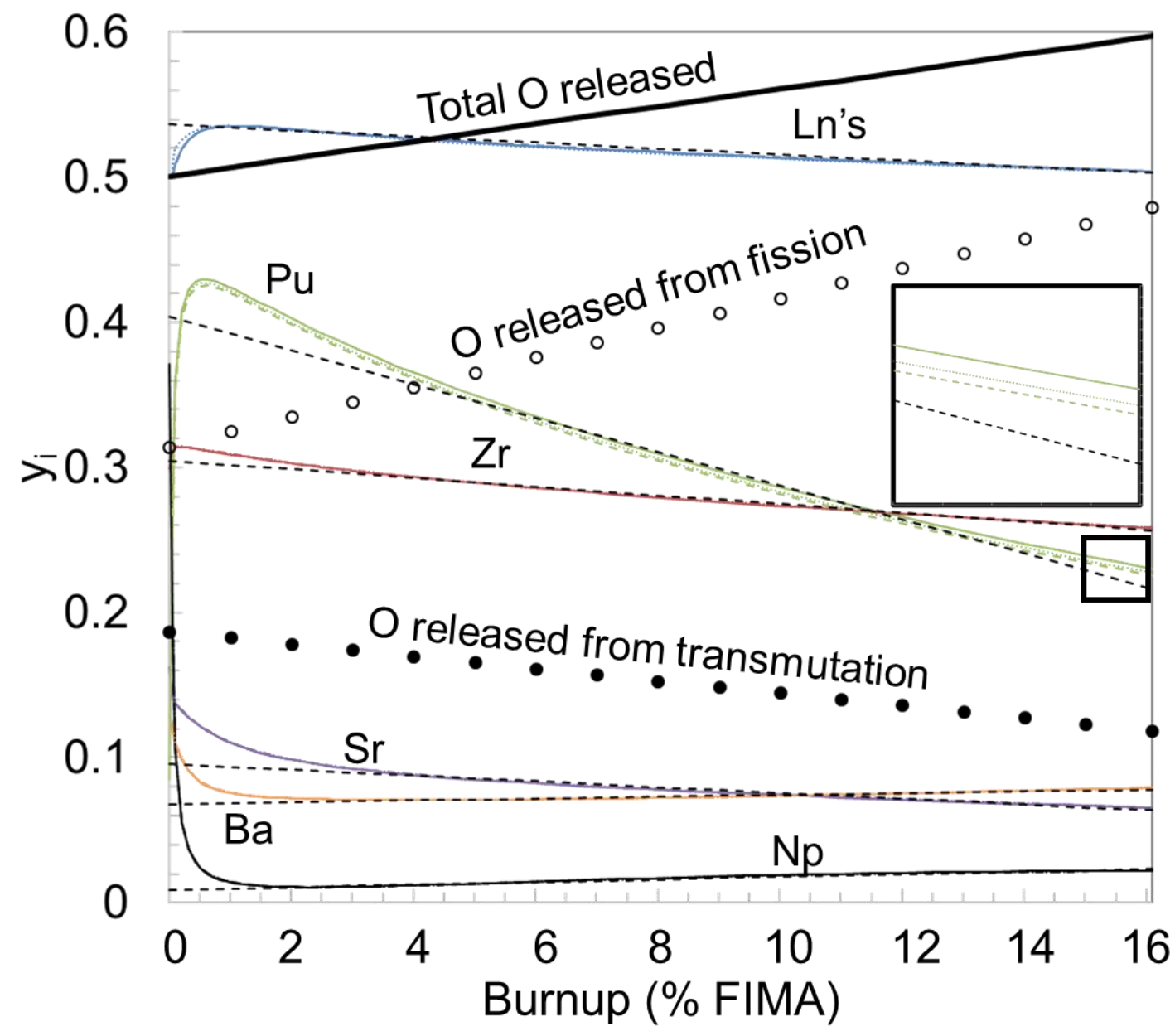


Figure 2. MHTGR block modeled in Serpent.

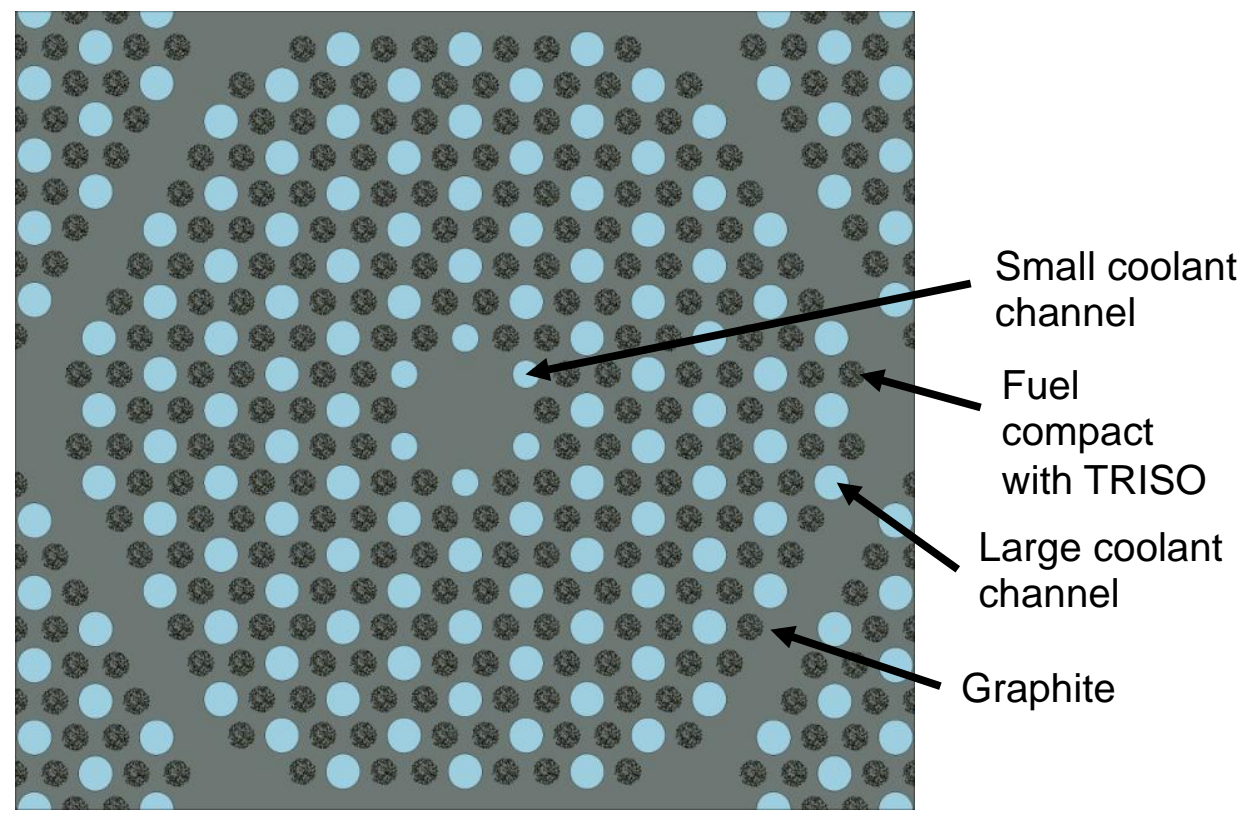


Figure 3. BOL (0\% FIMA) and EOL (16.1\% FIMA) neutron flux spectrum for an example configuration from the reactor physics analyses $\left(80 \% \mathrm{UO}_{2}-20 \% \mathrm{UC}_{1.9}\right)$.

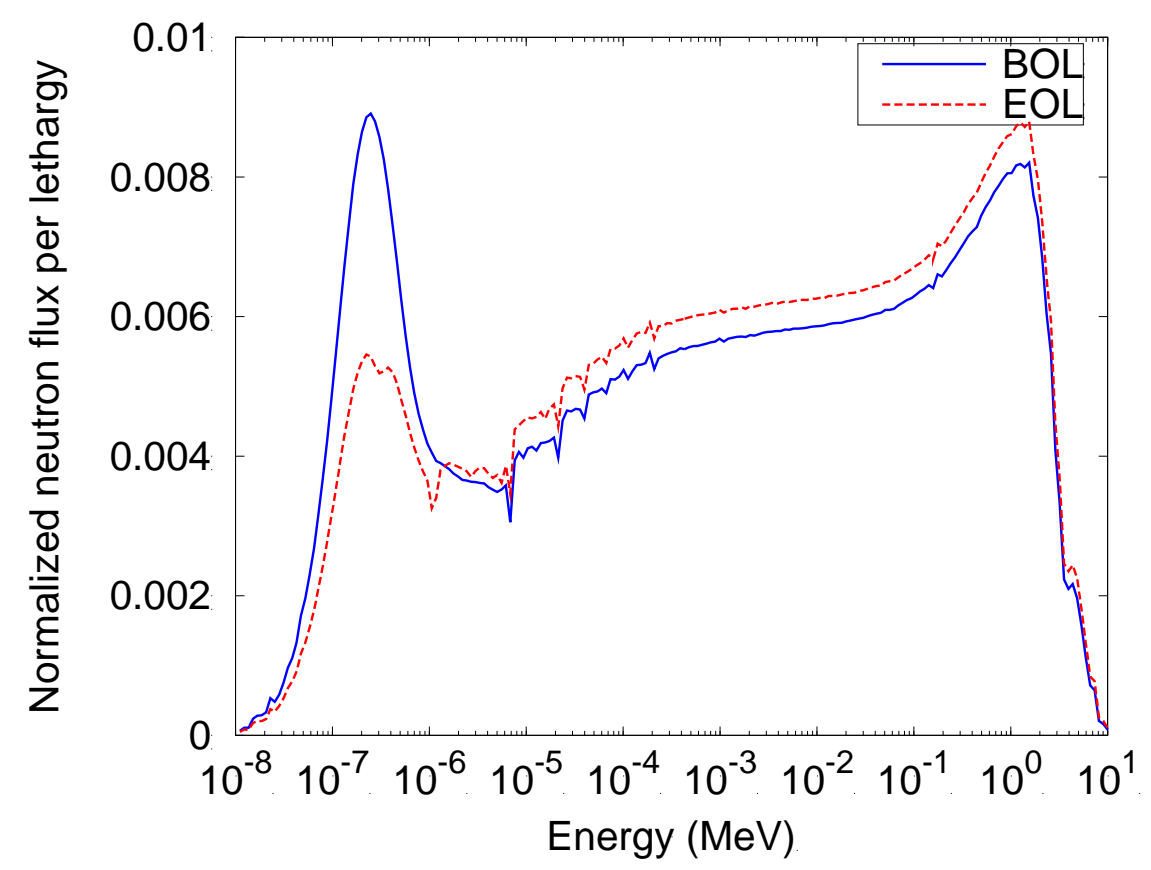


Figure 4 Ellingham-Richardson diagram for the oxide forming FPs in equilibrium with their carbides. Note that the $\mathrm{O}_{2}$ partial pressure is referenced to one atmosphere and these are the temperatures of interest to HTGR designers. The nominal $\mathrm{UC}_{2}$ line is calculated either as that compound or $\mathrm{U}_{2} \mathrm{C}_{3}$ depending on phase stability.

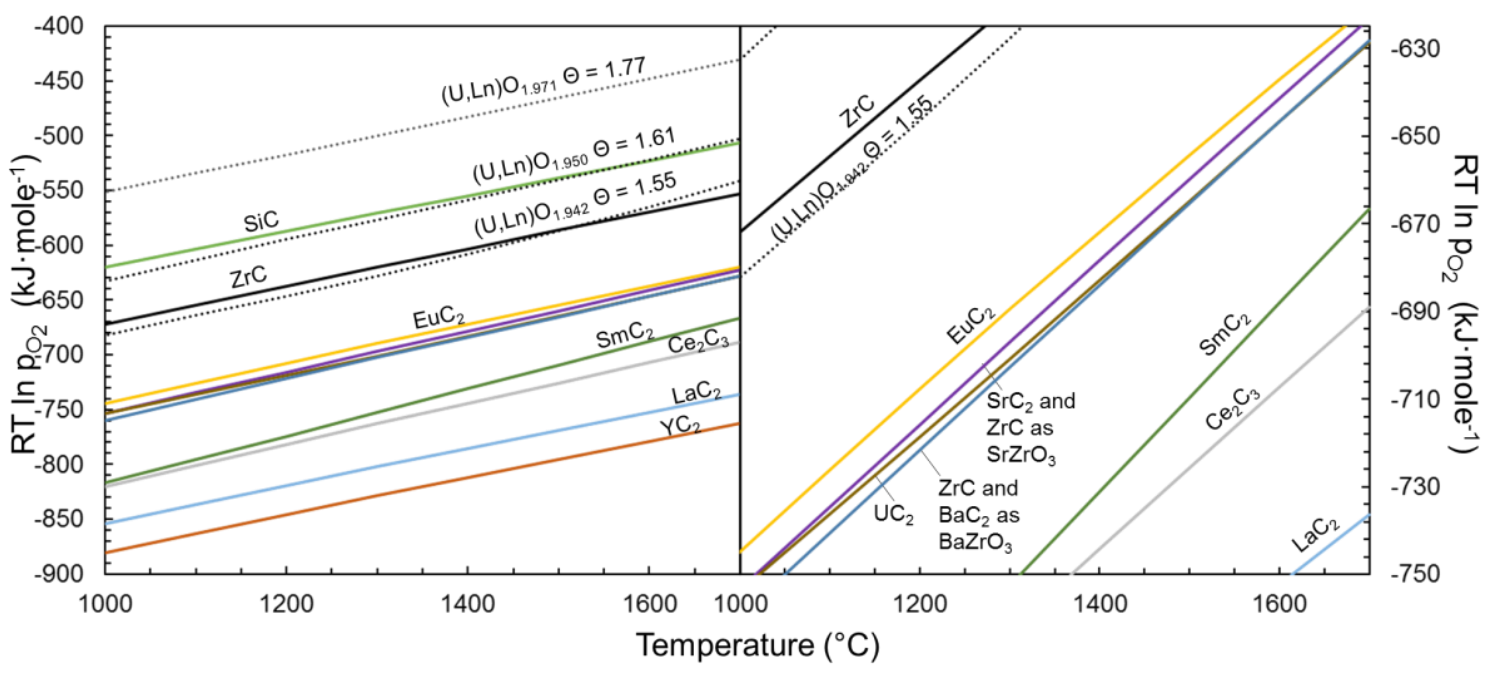


Figure 5 Logarithm of the $\mathrm{CO}$ pressures for the oxide forming FPs in equilibrium with their carbides. As in Fig. 4, the nominal $\mathrm{UC}_{2}$ line is calculated either as that compound or $\mathrm{U}_{2} \mathrm{C}_{3}$ depending on phase stability.

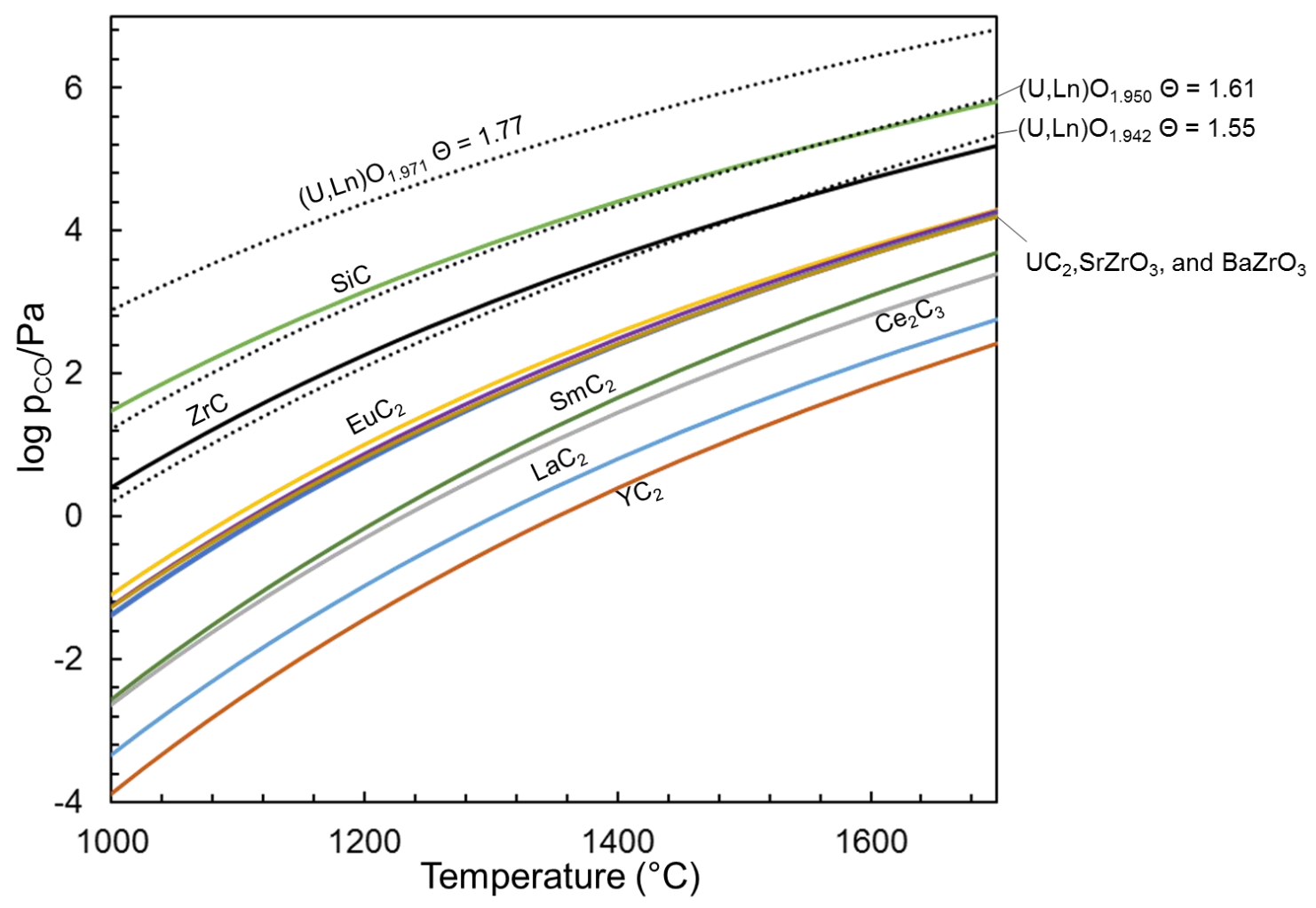


Figure 6. Instantaneous fraction of fissions during each burnup step for an example configuration from the reactor physics analyses $\left(80 \% \mathrm{UO}_{2}-20 \% \mathrm{UC}_{1.9}\right)$.

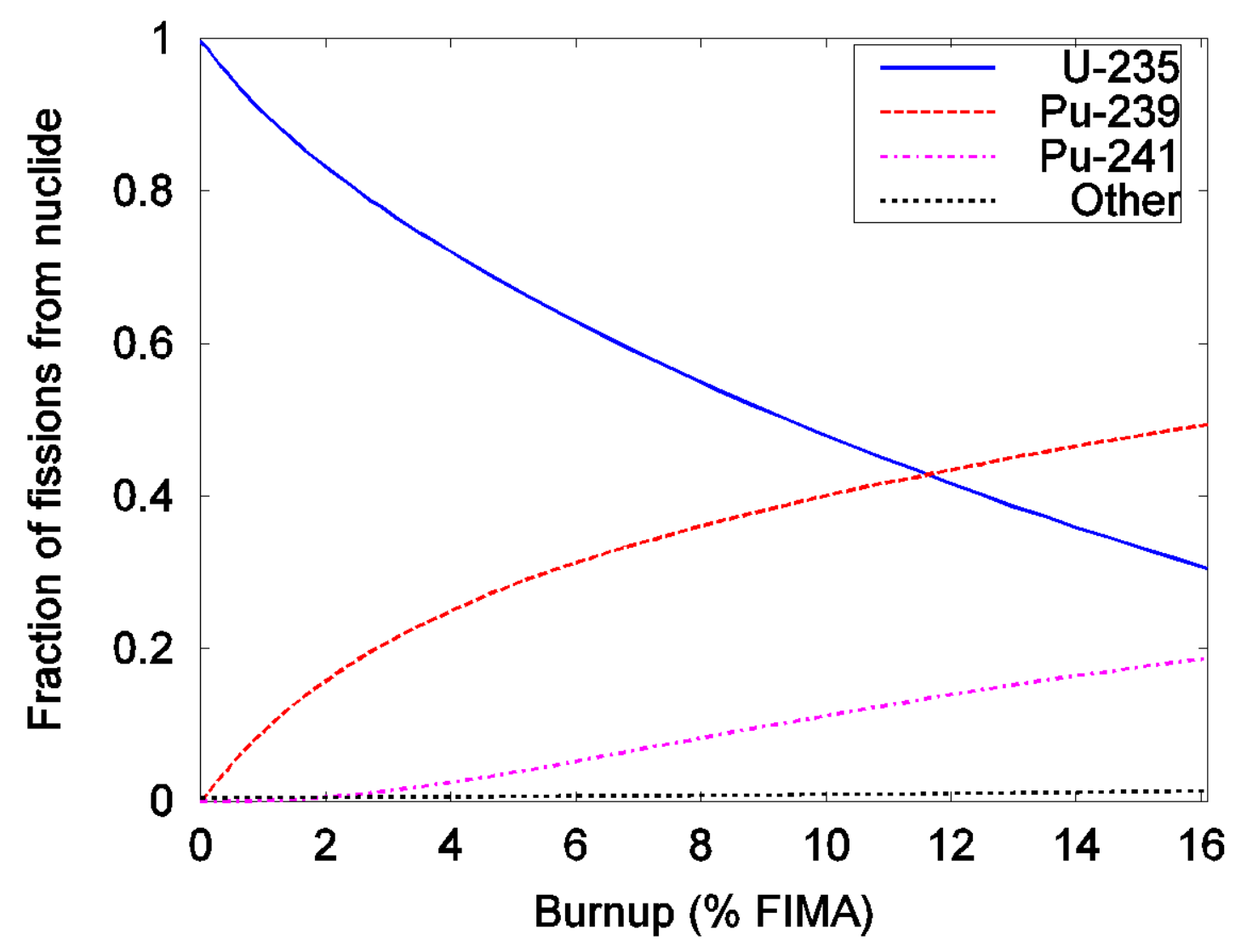

